\title{
Level Stres dan Strategi Coping pada Caregiver Stroke Rumah Sakit Pelamonia Makassar
}

\section{Stress Level and Coping Strategy on the Caregivers of Stroke at Pelamonia Hospital Makassar}

\author{
Yunitia Insani ${ }^{1}$, Nurmulia Wunaini ${ }^{2}$ \\ ${ }^{12}$ STIKES Pelamonia Kesdam VII Wirabuana Makassar \\ Email: insanitya2689@gmail.com,nurmuliawunaini@gmail.com \\ Jalan Garuda No. 3 AD Makassar Sulawesi Selatan
}

\begin{abstract}
ABSTRAK
Stroke sering terjadi secara spontan dan tidak terprediksi. Selain membawa dampak psikologis bagi pasien itu sendiri, stroke juga membawa dampak bagi keluarga pasien. Menurut data Riset Kesehatan Dasar Tahun 2013, prevalensi stroke di Indonesia 12,1 per 1.000 penduduk. Data yang didapatkan dari Rumah Sakit Pelamonia mengenai jumlah pasien stroke selama tahun 2018 sebanyak 2379 orang. Agar pasien stroke dapat melangsungkan kehidupannya maka diperlukan seseorang yang dapat membantu segala aktivitasnya disebut caregiver. Beban caregiver mengacu pada perasaan negatif dan ketegangan yang dialami seseorang ketika merawat seseorang yang stroke. Desain penelitian yang digunakan adalah mix method (kualitatif dan kuantitatif) untuk menggali informasi secara mendalam mengenai level dan strategi coping stres caregiver pasien stroke yang menjalani pengobatan di Rumah Sakit TK. II Pelamonia Makassar dengan pendekatan studi kasus melalui pengisian kuesioner dan wawancara mendalam. Alasan pemilihan lokasi penelitian ini adalah tingginya jumlah pasien stroke di Rumah Sakit TK. II Pelamonia Kota Makassar. Hasil penelitian menunjukkan bahwa caregiver pasien stroke di Rumah Sakit TK. II Pelamonia Makassar menggunakan strategi coping yang berpusat pada masalah dan emosi. Strategi coping yang berpusat pada masalah dilakukan melalui menyanyi, mengobrol dengan tetangga, menangis, dan mengatur waktu untuk aktifitas lainnya. Strategi coping yang berpusat pada emosi dilakukan melalui mencari dukungan sosial dari keluarga.
\end{abstract}

Kata Kunci: Coping_Caregiver, Stroke, Level Stres

\section{ABSTRACT}

Strokes often occur suddenly and unpredictably. Aside of bringing psychological effects to the patient itself, strokes also give impact toward the patient's family. According to the 2013's Basic Health Research Data, the prevalence of stroke in Indonesia is about 12.1 per 1,000 population. The obtained data from Pelamonia Hospital regarding to the number of stroke patients during 2018 were about 2.379 people. Stroke patients, in order to carry out their lives, need someone capable to help all of their activities, namely caregivers. Burden of the caregivers refers to the negative feelings and tension experienced by the people as they are treating someone with a stroke. The research design used is a mix method (qualitative and quantitative) to explore a profound information on the level and the coping strategies of stress on the caregiver for stroke patients whom undergoing treatment at Pelamonia Hospital, with a case-study approach conducted through questionnaires and in-depth interviews. The reason for choosing the location of this research is due to the high number of stroke patients at Pelamonia Hospital, Makassar City. The results of this research show that the caregivers of stroke patients at Pelamonia Hospital use coping strategies focused on problems and emotions. Problem-focused coping strategies are accomplished through singing, chatting with neighbors, crying, and setting time for other activities. Whereas, emotion-focused coping strategies are conducted through seeking the family's social support.

Keywords: Coping, Caregiver, Stroke, Stress Level 
Yunitia Insani, Nurmulia Wunaini : Stress Level and Coping Strategy on ..

\section{PENDAHULUAN}

Stroke sering terjadi secara spontan dan tidak terprediksi. Selain membawa dampak psikologis bagi pasien itu sendiri, hal ini juga membawa dampak bagi keluarga pasien. Penyakit stroke merupakan penyebab kematian nomor tiga di dunia dan penyebab paling sering kecacatan pada orang dewasa (Fajriyati, 2017). Stroke tidak mengenal batas dimana setiap 2 detik seseorang di dunia mengalami stroke. Secara global seseorang meninggal karena penyebab utama kecacatan ini setiap 5 detik, mengakhiri 6,4 juta nyawa setiap tahun (Julianti, 2015).

Individu terkena stroke mengalami penurunan aktivitas baik secara fisik, mental maupun sosial yang mengakibatkan individu tersebut tidak mampu lagi untuk menjalankan kegiatannya sehari-hari secara mandiri. Agar pasien stroke dapat melangsungkan kehidupannya maka diperlukan seseorang untuk membantu segala aktivitasnya. Seseorang yang menyediakan bantuan bagi penderita penyakit kronis seperti stroke disebut caregiver (Ayuningputri \& Maulana, 2013).

Pada kasus stroke, caregiver harus menemani pasien selama hampir 24 jam untuk memenuhi segala kebutuhan pasien. Peran keluarga difokuskan pada upaya pemberian perawatan untuk mengembalikan kualitas hidup pasien dan meningkatkan upaya penyembuhan pasien. Bentuk peran keluarga dilakukan dengan membantu aktivitas fisik, personal hygiene pasien, kepatuhan pengobatan, dan memenuhi kebutuhan emosional pasien. Beban caregiver mengacu pada perasaan negatif dan ketegangan dialami seseorang ketika merawat seseorang yang sakit kronis seperti stroke, merupakan salah satu masalah kesehatan masyarakat, dan penyebab utama kecacatan jangka panjang. Perawatan stroke komprehensif atau perawatan holistik membutuhkan perawatan yang sangat efektif. Oleh karenanya, caregiver memainkan peran penting dalam rehabilitasi pasca stroke. Selain itu, rawat inap juga memberi beban pada pasien. Caregiver pasien dengan penyakit neurologis telah ditemukan memiliki risiko isolasi sosial yang lebih tinggi, beban emosional dan penurunan kualitas hidup (Astuti, 2010).

Penelitian yang dilakukan oleh Kristina Adi Nugraha dari Kementerian Kesehatan Politeknik Kesehatan Surakarta Jurusan Keperawatan dilakukan untuk mengetahui hubungan antara kecerdasan emosional dan pengasuh asuhan 
Jurnal Manajemen Kesehatan Yayasan RS.Dr.Soetomo Vol.6 No.1 April 2020 :

penderita stroke hemoragik di RSUD Soediran Mangun Sumarso Wonogiri. Hasil penelitian menunjukkan bahwa caregiver memiliki strategi coping yang baik berupa emotional focused coping dan problem focused coping yakni dimana kecerdasan emosional yang baik akan berpengaruh pada coping yang dilakukan misalnya dengan mengelola emosi agar lebih sabar (Wijanarko \& Ediati, 2016).

Selain itu, penelitian Fahrunnisa dari Fakultas Psikologi Universitas Ahmad Dahlan, Yogyakarta dilakukan untuk mengetahui kondisi stres dan strategi coping yang digunakan oleh caregiver yang merawat pasangan yang terkena stroke. Hasil penelitian menunjukkan bahwa religiouscoping membantu dalam menangani pasien stroke dan strategi lain dipengaruhi oleh dukungan sosial dan kondisi ekonomi yang melatar belakangi subjek. Subjek penelitian ini terbatas hanya 4 orang yang terdiri dari pasangan pasien stroke dan significant person yang berjenis kelamin wanita sehingga tidak menunjukkan hasil yang sifatnya umum atau berlaku untuk semua jenis kelamin (Yuliasari, Wahyuningsih, \& Sulityarini, 2018).

Data yang didapatkan dari Rumah Sakit Pelamonia mengenai jumlah pasien stroke selama tahun 2018 sebanyak 2379 orang. Agar pasien stroke dapat melangsungkan kehidupannya maka diperlukan seseorang yang dapat membantu segala aktivitasnya yakni caregiver. Tujuan penelitian ini adalah untuk mengukur level stres dan bentuk-bentuk strategi coping pada caregiver pasien stroke di Rumah Sakit Pelamonia,maka penelitian ini diharapkan mampu menjadi rujukan intervensi bagi pihak rumah sakit untuk membantu caregiver dalam menangani stresnya saat merawat pasien stroke.

\section{METODE}

Desain penelitian ini adalah mix method (kuantitatif dan kualitatif) untuk mengukur level stres dan menggali informasi secara mendalam mengenai strategi coping stres caregiver pasien stroke yang menjalani pengobatan di Rumah Sakit TK. II Pelamonia Makassar tahun 2019 dengan pendekatan studi kasus. Penelitian ini dilakukan di Rumah Sakit Pelamonia yang berlokasi di Jalan Jend. Sudirman No.27, Kota Makassar, Sulawesi Selatan pada tanggal 18 Juni 2019 hingga 27 Juli 2019 dengan jumlah populasi dari Januari hingga April 2019 sebanyak 133 pasien 
Yunitia Insani, Nurmulia Wunaini : Stress Level and Coping Strategy on ..

rawat inap dan 556 pasien rawat jalan. Instrumen dalam penelitian kuantitatif menggunakan kuesioner DASS (Depretion Axtienty Sress Scale) 42 yang diukur dari 46 responden terkait pengukuran level stres dengan pendekatan deskriptif. Hasil penelitian kuantitatif dianalisis menggunakan SPSS dan disajikan dalam bentuk univariat yakni karakteristik responden dan level stres caregiver. Instrumen penelitian dalam penelitian kualitatif menggunakan analisis tematik dan disajikan dalam bentuk tabel dan teks naratif. Hasil penelitian kualitatif diukur dari hasil wawancara mendalam (indept interview) dengan 8 orang informan kunci. Sementara data sekunder dari data pasien stroke di Rumah Sakit Pelamonia. Informan kunci dalam penelitian ini adalah caregiver atau penjaga informal pasien stroke yang tidak menerima pendidikan sebagai tenaga caregiver.

HASIL

Tabel 1. Karakteristik Responden

\begin{tabular}{lcc}
\hline Jenis Kelamin & $\mathbf{n}$ & $\mathbf{\%}$ \\
\hline Laki-laki & 5 & 10.9 \\
Perempuan & 41 & 89.1 \\
Total & 46 & 100.0 \\
\hline Pendidikan Terakhir & $\mathbf{n}$ & $\mathbf{\%}$ \\
\hline Tidak Sekolah & 1 & 2.2 \\
Tamat SD & 7 & 15.2 \\
Tamat SMP/Sedajat & 7 & 15.2 \\
Tamat SMA/Sederajat & 17 & 37.0 \\
Diploma/S1/S2 & 14 & 30.4 \\
Total & 46 & 100.0 \\
\hline Kategori Usia & $\mathbf{n}$ & $\mathbf{\%}$ \\
\hline Remaja Akhir (17-25 Tahun) & 4 & 8.7 \\
Dewasa Awal (26-35 Tahun) & 8 & 17.4 \\
Dewasa Akhir (36-45 Tahun) & 12 & 26.1 \\
Lansia Awal (46-55 Tahun) & 13 & 28.3 \\
Lansia Akhir (56-65 Tahun) & 9 & 19.6 \\
Total & 46 & 100.0 \\
\hline Hubungan dengan Pasien & $\mathbf{n}$ & $\mathbf{\%}$ \\
\hline Suami/Istri & 19 & 41.3 \\
Orangtua/Mertua & 22 & 47.8 \\
Kakek/nenek & 1 & 2.2 \\
Saudara/sepupu & 3 & 6.5 \\
Lainnya & 1 & 2.2 \\
\end{tabular}




\begin{tabular}{lcc} 
Total & 46 & 100.0 \\
\hline Level Stres Caregiver & $\mathbf{n}$ & $\mathbf{\%}$ \\
\hline Normal & 42 & 91.3 \\
Ringan & 4 & 8.7 \\
Sedang & 0 & 0 \\
Parah & 0 & 0 \\
Sangat parah & 0 & 0 \\
Total & 46 & 100.0 \\
\hline
\end{tabular}

Berdasarkan Tabel 1 menunjukkan bahwa sebagian besar jenis kelamin responden adalah perempuan (89,1\%), dengan tingkat pendidikan terakhir yang terbanyak adalah tamat SMA/sederajat (37\%). Kategori usia tertinggi yakni Lansia Awal (46-55 Tahun) sebesar 28,3\%. Adapun Sebagian besar caregiver merupakan anak/menantu dari pasien stroke (47,8\%) dan suami/istri dari pasien stroke (41,3\%). Hasil kuesioner DASS (Depretion Axtienty Sress Scale) menunjukkan sebagian besar responden berada pada level stres yang normal.

Tabel 2 Karakteristik Informan

\begin{tabular}{lccccc}
\hline Informan & $\begin{array}{c}\text { Jenis } \\
\text { Kelamin }\end{array}$ & $\begin{array}{c}\text { Pendidikan } \\
\text { Terakhir }\end{array}$ & $\begin{array}{c}\text { Usia } \\
\text { (tahun) }\end{array}$ & $\begin{array}{c}\text { Hubungan } \\
\text { dengan } \\
\text { Pasien }\end{array}$ & Level Stres \\
\hline Informan 1 & Perempuan & SMK & 22 & Cucu & Normal \\
Informan 2 & Perempuan & SMA & 42 & Menantu & Normal \\
Informan 3 & Perempuan & SMK & 28 & Anak & Normal \\
Informan 4 & Perempuan & SMA & 46 & Anak & Normal \\
Informan 5 & Perempuan & SLTA & 44 & Anak & Normal \\
Informan 6 & Perempuan & S1 & 53 & Istri & Normal \\
Informan 7 & Perempuan & D3 & 77 & Istri & Normal \\
Informan 8 & Perempuan & SD & 44 & Istri & Ringan \\
\hline
\end{tabular}

Berdasarkan Tabel 2 bahwa semua informan berjenis kelamin perempuan dan merupakan keluarga dekat dari pasien, baik itu anak, istri maupun menantu dan cucu. Sebagian besar berpendidikan terakhir SMA sederajat dengan batasan usia rata-rata dewasa akhir dan dengan level stres yang normal.

Tabel 3 Pemicu Stres Caregiver Pasien Stroke di Rumah Sakit TK. II Pelamonia Makassar

\begin{tabular}{ll}
\hline Informan & Pemicu Stres \\
\hline Informan 1 & Pasien selalu butuh teman cerita \\
Informan 2 & Tidak ada pemicu yang begitu serius \\
Informan 3 & Pasien rewel
\end{tabular}


Yunitia Insani, Nurmulia Wunaini : Stress Level and Coping Strategy on ..

\begin{tabular}{|ll}
\hline Informan & Pemicu Stres \\
\hline Informan 4 & $\begin{array}{l}\text { Mengatur waktu antara menjaga pasien dan mengurus keluarga, } \\
\text { pasien lebih mudah marah }\end{array}$ \\
Informan 5 & Ketika pasien kesakitan karena sakitnya \\
Informan 6 & Pasien mudah marah dan sensitif \\
Informan 7 & Pasien susah diatur \\
Informan 8 & Pasien mudah marah dan sensitif \\
\hline
\end{tabular}

Hasil penelitian menunjukkan bahwa pemicu stres caregiver berasal dari beberapa faktor seperti stres menghadapi pasien yang mudah marah, susah diatur, pasien rewel atau kesulitan mengatur waktu jaga. Berdasarkan hasil wawancara dengan 8 informan ditemukan bahwa 7 dari 8 informan mengaku pernah mengalami stres selama menjadi caregiver. Berdasarkan hasil wawancara dengan 8 informan ditemukan bahwa beberapa pemicu stres caregiver ditengarai oleh sulitnya mengatur waktu dengan aktifitas lain, jika penyakit kambuh dan pasien merasakan sakit pada beberapa anggota tubuh, pasien sulit diatur dan tidak sabaran, mudah marah atau sensitif terhadap perlakuan tertentu.

\section{Tabel 4 Perilaku Coping Stres Caregiver Pasien Stroke yang Berorientasi pada Masalah (problem focused coping) di Rumah Sakit TK. II Pelamonia Makassar}

\begin{tabular}{|c|c|}
\hline Perilaku Coping & Hasil Wawancara \\
\hline Perilaku Aktif & $\begin{array}{l}\text { Sebagian besar responden melakukan perilaku-perilaku aktif } \\
\text { sebagai strategi tertentu untuk mengatasi stres selama menjaga } \\
\text { pasien seperti mengambil jeda dengan membawa pasien } \\
\text { menginap ke rumah saudara, menyanyi, mengobrol dengan } \\
\text { tetangga, mendiamkan saja, atau menangis di tempat terpisah, } \\
\text { baru kemudian jka situasi sudah mencair, caregiver akan } \\
\text { menjaga pasien seperti biasanya. }\end{array}$ \\
\hline Perencanaan & $\begin{array}{l}\text { Sebagian besar responden tidak membuat rencana khusus jika } \\
\text { sewaktu-waktu menghadapi stres. Sebagian responden } \\
\text { menanggapi dengan santai tanpa banyak pertimbangan rencana } \\
\text { sebelumnya. Bagi responden menjadi caregiver sudah menjadi } \\
\text { tanggung jawabnya sebagai keluarga sehingga tidak perlu } \\
\text { perencanaan khusus. Namun ada pula beberapa informan yang } \\
\text { karena pernah stres selama menjaga sehingga sudah terbiasa } \\
\text { dengan coping yang sebelumnya pernah dilakukan seperti } \\
\text { tidur, tidak menghiraukan, membiarkan saja, menonton tv, } \\
\text { bermain dengan anak, atau mengobrol dengan tetangga. }\end{array}$ \\
\hline $\begin{array}{l}\text { Penundaan terhadap } \\
\text { aktifitas lain yang } \\
\text { saling bersaing }\end{array}$ & $\begin{array}{l}\text { Beberapa cara yang dilakukan oleh responden dalam usaha } \\
\text { untuk menunda terhadap aktifitas lain yang sifatnya bersaing } \\
\text { misalnya diganti oleh saudara, mengatur waktu sebaik } \\
\text { mungkin, menyelesaikan pekerjaan caregiver lebih pagi dari } \\
\text { biasanya, meniggalkan aktifitas lain jikalau dirasa tidak bisa }\end{array}$ \\
\hline
\end{tabular}




\begin{tabular}{|c|c|}
\hline Perilaku Coping & Hasil Wawancara \\
\hline & $\begin{array}{l}\text { meninggalkan pasien, ataupun sebaliknya akan meninggalkan } \\
\text { pasien jika dirasa ada aktifitas lain yang sifatnya lebih } \\
\text { mendesak. }\end{array}$ \\
\hline Penge & $\begin{array}{l}\text { Sebagian besar dari mereka tidak membuat kiat atau cara } \\
\text { khusus untuk melatih diri mengontrol atau mengendalikan diri } \\
\text { agar mengatasi sumber stres selama menjaga pasien, kalaupun } \\
\text { ada biasanya hanya seperti membiarkan saja, ambil jeda untuk } \\
\text { tidur atau beristirahat, bersabar, atau menasihati pasien untuk } \\
\text { bersabar menghadapi penyakit yang dideritanya. }\end{array}$ \\
\hline $\begin{array}{l}\text { Mencari dukungan } \\
\text { sosial secara } \\
\text { instrumental }\end{array}$ & $\begin{array}{l}\text { Sebagian besar informan memperoleh bantuan berupa bantuan } \\
\text { merawat pasien, dibantu oleh keluarga dalam mengurangi } \\
\text { beban caregiversehari-hari seperti memasangkan popok, } \\
\text { makanan, pakaian, pemberian uang pengobatan, dan } \\
\text { pengantaran ke rumah sakit. }\end{array}$ \\
\hline
\end{tabular}

Berdasarkan Tabel 4 diketahui bahwa sebagian besar perilaku coping stres caregiver pasien stroke yang berorientasi pada masalah (problem focused coping) caregiver di Rumah Sakit TK. II Pelamonia Makassar adalah melakukan perilaku aktif untuk menangani masalah stresnya, merencanakan aktivitas lain jika sewaktu-waktu pemicu stresnya muncul, penundaan terhadap aktifitas lain yang saling bersaing, pengekangan diri untuk bersabar dan mencari dukungan sosial secara instrumental dalam bentuk bantuan akomodasi dari keluarga lain.

Tabel 5 Perilaku Coping Stres Caregiver Pasien Stroke yang Berorientasi pada Emosi (emotion focused coping) di Rumah Sakit TK. II Pelamonia Makassar

\begin{tabular}{ll}
\hline \multicolumn{1}{c}{ Perilaku Coping } & \multicolumn{1}{c}{ Hasil Wawancara } \\
\hline Mencari dukungan & $\begin{array}{l}\text { Sebagian besar informan mendapat bantuan emosional dari } \\
\text { sosial secara }\end{array}$ \\
emosional & $\begin{array}{l}\text { perhatian, kepedulian dan empati pada caregiver agar bersabar. } \\
\text { Reinterpretasi positif } \\
\text { Beberapa bentuk reinterpretasi positif yang dilakukan informan } \\
\text { adalah menguatkan diri atas kondisi pasien dengan }\end{array}$ \\
& $\begin{array}{l}\text { menganggap bahwa dengan menjadi caregiver adalah bagian } \\
\text { dari bentuk pengabdian kepada pasien, menerima keadaan, dan }\end{array}$ \\
& berpasrah diri. \\
Penerimaan diri & $\begin{array}{l}\text { Beberapa bentuk penerimaan diri dari informan seperti } \\
\text { menganggapnya sebagai bentuk balas jasa karena telah dirawat }\end{array}$ \\
& sejak belia, mengatur waktu sedemikian rupa, bersabar dan \\
Kembali kepada & Beberapa bentuk pengaruh ajaran agama yang dipahami \\
ajaran agama & informan adalah bahwa menjaga pasien adalah bentuk \\
& kewajiban dan pengabdian kepada pasien sebagai orangtua, \\
& menjadi ladang pahala dan menghindari dosa sebagai keluarga. \\
\hline
\end{tabular}


Yunitia Insani, Nurmulia Wunaini : Stress Level and Coping Strategy on ..

Berdasarkan Tabel 5 diketahui bahwa sebagian besar perilaku coping stres caregiver pasien stroke yang berorientasi pada emosi (emotion focused coping) caregiver di Rumah Sakit TK. II Pelamonia Makassar adalah mencari dukungan sosial secara emosional dalam bentuk perhatian dari keluarga, reinterpretasi positif dalam bentuk penguatan diri atas kondisi pasien, ikhlas menerima kondisi diri sebagai caregiver, serta penguatan rohani dan pendekatan agama untuk menguatkan bahwa segala upaya caregiver adalah bentuk pengabdian kepada pasien.

\section{PEMBAHASAN}

Stres yang dialami oleh caregiver disebabkan oleh beratnya tugas yang harus dilakukan dalam merawat pasien stroke (Nunung, 2019). Caregiver memiliki peranan yang penting dalam membantu kesembuhan pasien stroke, hal ini dikarenakan hampir seluruh kegiatan pasien dibantu oleh caregiver. Karakteristik responden (pada tabel 1) menunjukkan bahwa sebagian besar jenis kelamin responden adalah perempuan $(89,1 \%)$ dimana family caregiving alliance menunjukkan bahwa caregiver wanita jelas menanggung beban pengasuhan informal pada masyarakat dengan persentase 59\%-75\% dari pengasuh adalah perempuan (Julianti, 2015). Selain itu, caregiver berada pada pada kategori usia terbanyak yakni lansia awal (46-55 Tahun) sebesar 28,3\%.

Berdasarkan hasil penelitian Fajriyati menunjukkan bahwa caregiver secara emosional mengaku lebih sabar setelah merawat pasien stroke hal ini berkaitan dengan budaya masyarakat jawa dimana mereka akan menerima secara ikhlas apapun yang terjadi padanya sesuai ketentuan dari Tuhan atau dalam penelitian biasa kita sebut sebagai kontrol diri (Fajriyati, 2017). Sebagian besar caregiver merupakan anak/menantu dari pasien stroke $(47,8 \%)$ dan suami/istri dari pasien stroke (41,3\%) yang menunjukkan bahwa caregiver kunci merupakan orang terdekat dari pasien dimana dalam Schulz dan Sherwood menyebutkan bahwa hubungan suami istri menimbulkan efek yang sangat baik dalam perawatan. Hal ini juga sejalan pula dengan Wensley yang menekankan bahwa makna spiritualitas adalah bagian dari mengembangkan keterlibatan dalam keluarga yangmana dalam hal ini memungkinkan hubungan antara caregiver 
dengan pasien menjadi lebih dekat (Yuniarsih, 2014). Selanjutnya, hasil kuesioner DASS menunjukkan sebagian besar responden berada pada level stres yang normal. Dengan tingkat pendidikan terakhir yang terbanyak adalah tamat SMA/sederajat (37\%). Menurut Notoatmodjo, tingkat pendidikan merupakan salah-satu faktor dalam keberhasilan suatu perawatan yang baik, dimana semakin tinggi tingkat pendidikan maka semakin tinggi pula pengetahuannya (Hartati, 2015).

Berdasarkan hasil wawancara juga ditemukan bahwa tidak ada kesulitan bagi caregiver dalam upaya penerimaan diri karena sebagian caregiver adalah golongan masa paruh baya yang mana dalam proses perkembangannya sudah ada di tingkatan keinginan untuk merawat orang lain, seperti cucu atau pasangan. Serangkaian studi terdahulu yang didasarkan pada skala Ryff menunjukkan masa paruh baya (dewasa madya) secara umum berada pada periode kesehatan mental positif. Hal ini menjelaskan teori perkembangan Erikson yang mengatakan bahwa tugas perkembangan utama pada usia paruh baya adalah mencapai generatifitas, yaitu keinginan untuk merawat dan membimbing orang lain (Ayuningputri \& Maulana, 2013).

Penelitian ini didapatkan bahwa sebagian besar caregiver tidak merasa terbebani dan stres karena menjaga pasien. Data ini didukung dari tabel 1 yang menunjukkan bahwa 5 dari 8 caregiver berada kategori usia dewasa akhir dan lansia awal (36-55 tahun) yang merasa ikhlas dalam merawat pasien stroke. Berdasarkan hasil penelitian Fajriyati menunjukkan bahwa caregiver secara emosional mengaku lebih sabar setelah merawat pasien stroke hal ini berkaitan dengan budaya masyarakat jawa dimana mereka akan menerima secara ikhlas apapun yang terjadi padanya sesuai ketentuan dari Tuhan atau dalam penelitian biasa kita sebut sebagai kontrol diri (Fajriyati, 2017).

Lazarus menjelaskan fungsi coping menjadi dua fungsi yaitu coping yang terpusat pada masalah dan coping yang terpusat pada emosi. Bentuk perilaku coping yang berorientasi pada masalah (problem focused coping) yang dilakukan oleh informan adalah perilaku aktif, perencanaan, penundaan terhadap aktifitas lain yang saling bersaing, pengekangan diri, dan mencari dukungan sosial secara 
Yunitia Insani, Nurmulia Wunaini : Stress Level and Coping Strategy on ..

instrumental. Bentuk perilaku coping yang berorientasi pada emosional (emotion focused coping) yang dilakukan oleh informan adalah perilaku mencari dukungan sosial secara emosional, reinterpretasi positif, penerimaan diri, dan kembali kepada ajaran agama (Maryam, 2018).

Salah satu bentuk perilaku coping yang berorientasi pada emosional adalah dukungan sosial secara emosional. Dukungan sosial secara emosionalpada umumnya menggambarkan pengaruh emosi yang dapat ditimbulkan oleh orang lain, baik itu dari keluarga maupun orang-orang terdekat. Dukungan ini diberikan dengan tujuan agar caregiver merasa diperhatikan, disayangi dan dicintai dan menimbulkan sikap menerima keadaan dirinya. Adapun bentuk dukungan sosial yang diberikan kepada caregiver berasal dari keluarga dan tetangga dengan memberikan semangat dan empati kepada caregiver agar menerima keadaannya sebagai penjaga pasien. Penelitian ini didukung oleh penelitian yang dilakukan oleh Masyithah tentang hubungan dukungan sosial dan penerimaan diri pada penderita pasca stroke yang menyatakan bahwa ada hubungan antara dukungan sosial dan penerimaan diri terhadap penderita pasca stroke pada pasien rawat jalan Rumah Sakit Islam Jemursari Surabaya. Berarti bahwa semakin tinggi dukungan sosial yang diberikan pada penderita pasca stroke, maka semakin tinggi pula penerimaan diri yang dimunculkan oleh penderita (Masyithah, 2012).

Perilaku coping yang berorientasi pada emosional selanjutnya adalah reinterpretasi positif. Reinterpretasi positif merupakan strategi coping adaptif yang digunakan untuk menghadapi tekanan emosional dan berfokus pada aspekaspek positif dari situasi sulit yang dialami oleh caregiver selama menjaga pasien. Beberapa metode yang dilakukan oleh caregiver seperti berupaya untuk menahan amarah, terus memberikan semangat kepada pasien agar cepat pulih, mencari hiburan, dan menganggapnya sebagai bentuk pengabdian kepada pasien sebagai anak atau pasangan. Penelitian dari Kholidah yang berjudul berpikir positif untuk menurunkan stres psikologis menunjukkan hasil bahwa pelatihan berpikir positif efektif untuk menurunkan tingkat stres pada mahasiswa. Pelatihan berpikiran positif signifikan berperan membuat individu dapat menerima situasi yang tengah dihadapi secara lebih positif (Kholidah \& Alsa, 2012). 
Selanjutnya, perilaku coping yang berorientasi pada emosional adalah penerimaan diri. Hurlock menyatakan adanya sejumlah faktor yang dapat mempengaruhi penerimaan diri seseorang, diantaranya adalah harapan yang realistis, keberhasilan, pengenalan diri, wawasan sosial dan konsep diri yang stabil (Wijanarko \& Ediati, 2016). Berdasarkan hasil wawancara ditemukan bahwa beberapa caregiver merasa cukup mampu untuk menyesuaikan waktunya antara bekerja dan menjaga pasien. Bagi caregiver, orangtua adalah prioritas hidup. Cara terbaik dalam penerimaan diri adalah dengan menyesuaikan waktu sebaik mungkin karena menjaga pasien dianggap sebagai kewajiban dan bentuk balas jasa. Berdasarkan hasil wawancara juga ditemukan bahwa tidak ada kesulitan bagi caregiver dalam upaya penerimaan diri karena sebagian caregiver adalah golongan masa paruh baya yang mana dalam proses perkembangannya sudah ada di tingkatan keinginan untuk merawat orang lain, seperti cucu atau pasangan. Penelitian ini sejalan dengan penelitian yang dilakukan oleh Wijanarko dan Ediati tentang penerimaan diri pada orang tua yang memiliki anak skizofrenia. Penerimaan diri orangtua yang mempunyai anak dengan skizofrenia ditandai dengan penerimaan orangtua terhadap keadaan anak dengan skizofrenia. Tahapan penerimaan diri yang dilewati subjek yaitu penawaran, marah, dan penerimaan (Wijanarko \& Ediati, 2016).

Perilaku coping yang berorientasi pada emosional selanjutnya adalah kembali kepada ajaran agama.Pargament menjelaskan bahwa coping religus yang lebih positif akan meningkatkan kesehatan mental individu (Anantu, 2013). Pada dasarnya caregiver menyadari bahwa mereka menggunakan coping positif yang berfokus pada Tuhan dan meminta pengharapan kesembuhan bagi pasien. Sebagaimana penderita stroke, rutinitas dalam menjalani kehidupan tentu memberikan tekanan tersendiri karena adaptasi terhadap kondisi fisik yang tidak seperti saat sehat. Penelitian yang dilakukan Gholamzadeh dkk membuktikan bahwa penyelesaian masalah yang berbasis agama dapat mengatasi peristiwa yang menyakitkan dalam kehidupan caregiver.

Penelitian lain efektifitas pelatihan koping religius untuk meningkatkan kesejahteraan psikologis pada penderita Diabetes Mellitus Tipe 2 membuktikan 
Yunitia Insani, Nurmulia Wunaini : Stress Level and Coping Strategy on ..

bahwa terdapat perbedaan tingkat kesejahteraan psikologis yang signifikan antara penderita diabetes mellitus tipe 2 yang mendapat pelatihan koping religius dan yang tidak mendapatkan pelatihan koping religious (Yuliasari et al., 2018).

Bentuk perilaku coping yang berorientasi pada masalah (problem focused coping) salah satunya yakni perilaku aktif. Perilaku aktif pada caregiver stroke adalah proses dimana individu mengambil langkah aktif untuk mencoba untuk menghapus atau menghindari stressor dengan memperbaiki dampaknya. Pada penelitian ini sebagian besar responden melakukan perilaku aktif dalam bentuk mengambil jeda dengan membawa pasien menginap ke rumah saudara, menyanyi, mengobrol dengan tetangga, mendiamkan saja, sampai situasi sudah mencair. Menjaga jarak dengan melakukan coping ini dalam penyelesaian masalah, terlihat dari sikapnya yang kurang peduli terhadap persoalan yang sedang dihadapi bahkan mencoba untuk melupakannya (Maryam, 2018).

Perilaku coping yang berorientasi pada masalah selanjutnya adalah perencanaan (planning) dalam hal ini lebih kepada strategi atau tindakan sertacara terbaik dalam menghadapi stressor sebelum sumber stres muncul. Pada penelitian ini sebagian besar responden tidak membuat perencanaan tertentu dalam menghadapi stressor. Beberapa informan yang karena pernah stres selama menjaga sehingga sudah terbiasa dengan coping yang sebelumnya pernah dilakukan seperti tidur, tidak menghiraukan, menonton televisi, bermain dengan anak, atau mengobrol dengan tetangga. Penelitian lain menyatakan caregiver yang menggunakan strategi planning dimana individu memiliki strategi khusus jika menghadapi stressor serta berfokus pada penyelesaian masalah, maka tingkat kecemasannya menjadi lebih rendah dan adaptasi psikologis yang lebih baik (Pérez et al., 2019).

Selanjutnya adalah penundaan terhadap aktifitas lain yang saling bersaing (Suppresion of Competing) yang dimaksud dalam hal ini individu dapat menahan semua informasi yang bersifat kompetitif atau menahan semua informasi yang bersifat kompetitif agar caregiver bisa berkonsentrasi penuh terhadap masalah yang dihadapi. Beberapa cara yang dilakukan caregiver dalam usaha untuk menunda terhadap aktifitas lain yang sifatnya bersaing misalnya diganti oleh 
saudara, mengatur waktu sebaik mungkin, menyelesaikan pekerjaan caregiver lebih pagi dari biasanya, meninggalkan aktifitas lain jika dirasa tidak bisa meninggalkan pasien, ataupun sebaliknya akan meninggalkan pasien jika dirasa ada aktifitas lain yang sifatnya lebih mendesak, atau melakukan aktivitas seharihari seperti memasak di kesempatan lain. Seseorang yakin akan kemampuannya memiliki sikap optimis dalam menghadapi masa depan, kesulitan yang ada pasti dapat diatasi dan tidak mudah menyerah dalam menghadapi tantangan seperti manajemen waktu atau prioritas pada pasien stroke (Winda Lestari, 2014).

Mencari dukungan sosial secara instrumental (seeking social support for instumental reason) adalah dimana individu melakukan usaha untuk mendapat dukungan sosial berupa cara meminta nasehat, bantuan atau informasi dari orang lain. Dukungan sosial secara instrumental adalah dimana individu melakukan usaha untuk mendapat dukungan sosial berupa meminta nasehat, bantuan atau informasi dari orang lain. Dukungan sosial secara instrumental adalah dimana individu melakukan usaha untuk mendapat dukungan sosial berupa meminta nasehat, bantuan atau informasi dari orang lain.

Menurut Sarafino dalam Sukasni, 2019 orang dengan dukungan sosial yang tinggi ada kecenderungan tidak mengabaikan stress karena mereka tahu akan mendapatkan pertolongan dari orang lain (Septi Sri Indah Sukasni, 2019). Hasil penelitian ini menunjukkan bahwa berdasarkan hasil penelitian diketahui bahwa caregiver mendapat dukungan materi seperti dibantu dalam biaya pengobatan, dan akomodasi semisal pakaian namun dalam jumlah yang terbatas. Sebagian besar bantuan yang berupa bantuan dalam merawat dan mengurus kebutuhan pasien seperti membantu memandikan, mengambilkan barang dan menemani pasien.

\section{SIMPULAN}

Secara umum caregiver pasien stroke di Rumah Sakit Tk.II Pelamonia berada pada level stres normal. Ada dua bentuk strategi copingstress yang dilakukan oleh caregiver pasien stroke Rumah Sakit Tk.II Pelamonia yaitu strategi coping yang berorientasi pada emosi dan berorientasi pada masalah. Perilaku coping yang berorientasi pada masalah (problem focused coping) dilakukan secara konstruktif melalui bernyanyi, mengobrol dengan 
Yunitia Insani, Nurmulia Wunaini : Stress Level and Coping Strategy on ..

kerabat/tetangga, menangis, dan mengatur waktu untuk aktifitas lainnya. Perilaku coping yang berorientasi pada emosi (emotion focused coping) dilakukan melalui upaya mencari dukungan sosial dari keluarga, menganggap bahwa menjadi caregiver adalah bentuk pengabdian dan kewajiban kepada pasien, bersabar dan tidak berputus asa, dan menjadikannya sebagai upaya untuk memperoleh ladang pahala dari Tuhan.

\section{UCAPAN TERIMA KASIH}

Ucapan terima kasih penulis haturkan kepada semua pihak yang membantu terlaksananya penelitian ini terutama kepada Institusi Stikes Pelamonia Kesdam VII Wirabuana dan Direktorat Jendral Penguatan Riset dan Pengembangan Kementerian Riset, Teknologi, dan Pendidikan Tinggi.

\section{DAFTAR PUSTAKA}

Anantu, A. (2013). Hubungan antara frekuensi berdoa dengan adversity quotient pada karyawan beragama kristen dan katolik. Skripsi. Fakultas Psikologi. Universitas Sanata Dharma. Yogyakarta.

Astuti, Ri. (2010). Hubungan Jenis Stroke dengan Kecemasan pada Caregiver Pasien Stroke di RSUD DR. Moewardi Surakarta. https://doi.org/10.1093/occmed/kqq062.

Ayuningputri, N., \& Maulana, H. (2013). Persepsi Akan Tekanan Terhadap Kesejahteraan Psikologis Pada Pasangan Suami-Istri Dengan Stroke. JPPP Jurnal Penelitian Dan Pengukuran Psikologi, 2(2), 118. https://doi.org/10.21009/jppp.022.08

Fajriyati, Y. N. (2017). Coping Stres pada Caregiver Pasien Stroke. Indigenous: Jurnal Ilmiah Psikologi, 2(1), 96-105. Retrieved from http://journals.ums.ac.id/index.php/indigenous/article/view/5460/3759

Hartati, J. (2015). Hubungan Tingkat Pengetahuan Dengan Perilaku Family Caregiver Dalam Merawat Penderita Paska Stroke Dirumah. 1. Retrieved from

http://repository.uinjkt.ac.id/dspace/handle/123456789/25560\%0Ahttp://repo sitory.uinjkt.ac.id/dspace/bitstream/123456789/25560/1/Julia Hartati fkik.pdf

Julianti, E. (2015). Pengalaman Caregiver Dalam Merawat Pasien Pasca Stroke di Rumah pada Wilayah Kerja Puskesmas Benda Baru Kota Tangerang Selatan. Jurnal Universitas Islam Negeri Syarif Hidayatullah Jakarta. Retrieved from http://repository.uinjkt.ac.id

Kholidah, E., \& Alsa, a. (2012). Berpikir Positif untuk Menurunkan Stres Psikologis. Jurnal Psikologi, 39(1), 67-75. Retrieved from http://jurnal.psikologi.ugm.ac.id/index.php/fpsi/article/view/180 
Maryam, S. (2018). Strategi Coping: Teori Dan Sumberdayanya. JURKAM: Jurnal Konseling Andi Matappa. https://doi.org/10.31100/jurkam.v1i2.12

Masyithah, D. (2012). Hubungan dukungan sosial dan penerimaan diri pada penderita pasca stroke (Institut Agama Islam Negeri Sunan Ampel Surabaya; Vol. 99). Retrieved from http://digilib.uinsby.ac.id/9770/1/jiptiain-dewimasyit-10330-1-hubungan-e.pdf

Nunung, D. N. M. ini. S. F. (2019). No Title. Jurnal Keperawatan Padjadjaran, 2. https://doi.org/https://doi.org/10.24198/jkp.v2i3.86

Pérez-Cruz, M., Parra-Anguita, L., López-Martínez, C., Moreno-Cámara, S., \& Del-Pino-Casado, R. (2019). Coping and anxiety in caregivers of dependent older adult relatives. International Journal of Environmental Research and Public Health. https://doi.org/10.3390/ijerph16091651

Septi Sri Indah Sukasni. (2019). Hubungan antara Dukungan Sosial dengan Problem Focused Coping pada Remaja yang Tinggal di Panti Asuhan Budi Mulya Muhammadiyah Sukarame Bandar Lampung (Vol. 8). Retrieved from http://repository.radenintan.ac.id/5628/1/skripsi septi pdf.pdf

Wijanarko, A., \& Ediati, A. (2016). Penerimaan Diri Pada Orangtua Yang Memiliki Anak Skizofrenia. Jurnal Psikologi, 5(3), 424-429.

Winda Lestari, D. (2014). Penerimaan Diri Dan Strategi Coping Pada Remaja Korban Perceraian Orang Tua. eJournal Psikologi, Volume 2, 1-132(1), 113.

Yuliasari, H., Wahyuningsih, H., \& Sulityarini, R. I. (2018). Efektifitas Pelatihan Koping Religius untuk Meningkatkan Kesejahteraan Psikologis Pada Penderita Diabetes Mellitus Tipe 2. Journal of Psychological Science and Profession, 2(1), 73. https://doi.org/10.24198/jpsp.v2i1.15024

Yuniarsih, W. (2014). Pengalaman Caregiver Keluarga dalam Konteks Asuhan Keperawatan Pasien Stroke Tahap Paska Akut di RSUP Fatmawati.Thesis. Fakultas Ilmu Keperawatan. Universitas Indonesia. Depok.

\begin{tabular}{|l|l|}
\hline Submission & 30 Agustus 2019 \\
\hline Review & 20 Januari 2020 \\
\hline Accept & 11 Maret 2020 \\
\hline Publish & 23 April 2020 \\
\hline DOI & $10.29241 /$ jmk.v\%vi\%i.211 \\
\hline Sinta Level & 4 (Empat) \\
\hline
\end{tabular}

